\title{
Produção e qualidade de frutos de maracujazeiro-amarelo provenientes do cultivo com mudas em diferentes idades
}

Production and fruit quality of yellow passion fruit from the cultivation of seedlings at different ages

\section{Verônica Andrade dos Santos ${ }^{1 *}$, José Darlan Ramos ${ }^{1}$, Ranieri Reis Laredo ${ }^{1}$, Fábio Oseias dos Reis Silva ${ }^{2}$, Edvan Alves Chagas ${ }^{3}$ e Moacir Pasqual ${ }^{1}$}

Recebido em 04/07/2016 / Aceito em 30/08/2016

\section{RESUMO}

São muitos os fatores que influenciam a qualidade final do fruto do maracujazeiro. Dentre esses podem ser destacados a qualidade das mudas, o manejo e tratos culturais adequados. Sendo assim, o objetivo do trabalho foi avaliar qualidade de frutos de maracujazeiro-amarelo cultivados com mudas em diferentes idades. Para a formação das mudas foram utilizadas sementes do maracujazeiro-amarelo cv. Redondo Amarelo, substrato composto por terra+areia+esterco na proporção de $3: 1: 1$ e sacos plásticos com capacidade para $8 \mathrm{~kg}$. $\mathrm{O}$ delineamento experimental utilizado foi $\mathrm{em}$ blocos ao acaso (DBC), com cinco tratamentos, formado por mudas de diferentes idades $(25,50,75,100$ e 125 dias, após emergência), com quatro repetições de 12 plantas. As variáveis analisadas foram: massa fresca do fruto $(\mathrm{g})$ diâmetro longitudinal e transversal do fruto $(\mathrm{mm})$, índice de formato do fruto, espessura da casca $(\mathrm{mm})$, porcentagem de casca, suco e semente (\%), sólidos solúveis totais, acidez total titulável e pH. A utilização de mudas com idades de 100 e 125 dias após emergência no cultivo do maracujazeiroamarelo apresentou resultados satisfatórios para todas as características avaliadas, deduzindo-se ser viável sua utilização. O cultivo do maracujazeiro-amarelo formado com mudas de menor idade, em relação às demais obtiveram uma baixa produtividade, frutos menores e com menor rendimento de suco.

\section{ABSTRACT}

The factors influencing the final quality of the passion fruit are many, among them the quality of seedlings and the adequate management and farming practices stand out. So, the objective of this work was to evaluate the quality of yellow passion fruit cultivated with seedlings at different ages. For the establishment of the seedlings seeds of the yellow passion fruit $\mathrm{cv}$ were utilized. Redondo Amarelo, substrate composed of soil + sand + manure in the ratio of $3: 1: 1$ and plastic bags for up to $8 \mathrm{~kg}$ of weight. The experimental design utilized was in randomized blocks (DBC) with five treatments made up of different ages $(25,50,75,100$ and 125 days, after emergence) with four replications of twelve plants. The variables surveyed were: fresh mass of the fruit $(\mathrm{g})$ longitudinal and transversal diameter of the fruit ( $\mathrm{mm})$, fruit shape index, skin thickness $(\mathrm{mm})$, percentage of skin, juice and seed $(\%)$, total soluble solids, total titrable acidity and $(\mathrm{pH})$. The use of seedlings aged 100 and 125 days after emergence in yellow passion fruit cultivation showed satisfactory results for all characteristics, deducing feasible to use. The cultivation of yellow passion fruit formed with younger seedlings, compared to other ages obtained a low productivity, lower fruit and less juice yield.

KEYWORDS: Passiflora edulis, management, alternative cultivation.

PALAVRAS-CHAVE: Passiflora edulis, manejo, cultivo alternativo.

\footnotetext{
${ }^{1}$ Universidade Federal de Lavras, Lavras, MG, Brasil.

${ }^{2}$ Universidade Federal do Espírito Santo, São Mateus, ES, Brasil.

${ }^{3}$ Empresa Brasileira de Pesquisa Agropecuária, Boa Vista, RR, Brasil.

*Autor para correspondência <veronicaandrad@yahoo.com.br>
} 


\section{INTRODUÇÃO}

Atualmente a fruticultura é, dentre as atividades do setor primário, uma das principais potencialidades de geração de emprego e renda, com possibilidades do desenvolvimento da agroindústria processadora de frutas, favorecendo a expansão de pólos frutícolas em determinadas regiões do Brasil.

O maracujazeiro é originário da América Tropical, tendo mais de 150 espécies nativas do Brasil. A mais importante comercialmente, o maracujazeiro-amarelo (Passiflora edulis Sims $f$. flavicarpa Deg.), representando $95 \%$ dos pomares no país, sendo também a espécie mais plantada no mundo (BERNACCI et al. 2008, MELETTI et al. 2011).

Tradicionalmente, os principais países produtores mundiais de maracujá são: Brasil, Colômbia, Equador e Peru. Segundo o AGRIANUAL (2015) o maracujazeiro-amarelo é responsável por $95 \%$ da produção nacional. No Brasil, a área colhida no ano de 2013 foi de 57.277 hectares, com produção de 838.244 toneladas, o que equivale ao rendimento de 14,63 ton ha-1 (IBGE 2013).

A importância da cultura do maracujazeiro no Brasil vem crescendo. Entretanto, entre os problemas mais significativos no cultivo do maracujazeiro estão a baixa produtividade média obtida nos pomares, além da desuniformidade da qualidade dos frutos (NEVES et al. 2010).

Amaioria dos pomares encontra-se em pequenas áreas de agricultura familiar, sendo necessárias pesquisas que possam beneficiar e favorecer ao pequeno produtor. Ao longo dos anos, a cultura temse mostrado uma alternativa de renda para pequenos e médios produtores rurais, devido ao valor dos frutos comercializados. A produção brasileira de maracujá possui basicamente dois destinos: a indústria, principalmente a de extração de polpa para fabricação de suco e o consumo in natura com distribuição pelo mercado atacadista dos CEASAS. O suco e a polpa são utilizados no preparo de diversos produtos, entre os quais podem ser citados bebidas carbonatadas, bebidas mistas, xaropes, geléias, laticínios, sorvetes e alimentos enlatados.

Atualmente existe grande preocupação com a forma de implantação e condução dos pomares (ARAÚJO NETO et al. 2005). Entretanto informações sobre a utilização de mudas tardias no cultivo do maracujazeiro são escassas. Há necessidade de incremento nas pesquisas relacionado ao tema, pois as mudas convencionais estão sujeitas a inúmeras adversidades, dentre elas pode-se citar a morte prematura, contaminação com viroses e ataque de pragas.

A utilização de mudas com maior tempo de formação pode proporcionar antecipação da colheita, menor custo com insumos e favorece a melhoria na qualidade dos frutos em relação ao plantio convencional. Assim, o objetivo do trabalho foi estudar a produção e qualidade de frutos de maracujazeiro-amarelo cultivado com uso de mudas em diferentes idades.

\section{MATERIAL E MÉTODOS}

O experimento foi realizado no período de agosto de 2011 a abril 2012 no de setor de fruticultura do Departamento de Agricultura da Universidade Federal de Lavras - UFLA, Lavras, MG. Para a formação das mudas foram utilizadas sementes do maracujazeiro-amarelo cv. Redondo Amarelo, o substrato utilizado para o enchimento dos sacos plásticos pretos de polietileno com capacidade para $8 \mathrm{~kg}$ foi (terra+areia+esterco, 3:1:1). A semeadura foi realizada em intervalos de 25 dias. Em cada recipiente foram semeadas duas sementes, os sacos após semeadura do maracujazeiro-amarelo foram colocados sobre bancadas em ambiente tipo telado com sombrite de $50 \%$ de luminosiadade, estes foram irrigados diariamente de acordo com a necessidade da cultura. Após a emergência foi realizado o desbaste deixando a plântula mais vigorosa. Após quatro meses da primeira semeadura foi feita uma seleção rigorosa por idades e alturas para formar os tratamentos.

O delineamento utilizado para implantação em campo foi em blocos ao acaso, com cinco tratamentos que consistiam em diferentes idades das mudas (25, 50, 75, 100 e 125 dias após emergência), sendo quatro plantas por parcela e quatro repetições, todas as plantas foram levadas ao campo no mesmo dia. $\mathrm{O}$ sistema se sustentação utilizado foi o de espaldeira com um fio de arame em espaçamento de $5 \times 3 \mathrm{~m}$, sem irrigação. Foi realizada adubação na abertura das covas (20 litros de esterco de bovino curtido, $300 \mathrm{~g}$ de NPK e $300 \mathrm{~g}$ calcário) 60 dias antes do plantio. A adubação recomendada para cultura foi realizada de acordo com o resultado da análise de solo, conforme Tabela 1.

Quatro meses após plantio em dezembro 2011 foram realizadas as primeiras avaliações. Para todos 
Tabela 1 - Análise química do solo na área do plantio, UFLA. Lavras, MG, 2012.

Table 1 - Chemical analysis of the soil in the planting area, UFLA. Lavras, MG, 2012.

\begin{tabular}{cccccccccccccc}
\hline $\mathrm{pH}$ & $\mathrm{P}$ & $\mathrm{K}$ & $\mathrm{Ca}^{+2}$ & $\mathrm{Mg}^{+2}$ & $\mathrm{Al}^{+3}$ & $\mathrm{H}+\mathrm{Al}$ & $\mathrm{SB}$ & (t) & $\mathrm{T}$ & $\mathrm{V}$ & $\mathrm{m}$ & $\mathrm{MO}$ & $\mathrm{P}-\mathrm{rem}$ \\
\hline & água & $\mathrm{mg} / \mathrm{dm}^{3}$ & & & & $\mathrm{cmol}_{\mathcal{c}} / \mathrm{dm}^{3}$ & & & & $\%$ & $\mathrm{dag} / \mathrm{kg}$ & $\mathrm{mg} / 1$ \\
\hline 5,4 & 1,71 & 26 & 0,5 & 0,1 & 0,1 & 2,32 & 0,67 & 0,77 & 2,99 & 22,3 & 12,99 & 0,86 & 17,86 \\
\hline
\end{tabular}

os tratamentos foram avaliados: massa do fruto (g), diâmetro longitudinal e transversal do fruto $(\mathrm{mm})$, índice de formato, espessura da casca $(\mathrm{mm})$, porcentagem de casca, suco e semente $(\%)$, sólidos solúveis totais, acidez total titulável ( $\%$ de ácido cítrico), potencial hidrogeniônico $(\mathrm{pH})$, número de frutos por planta em condições de consumo e produtividade $\mathrm{kg} \mathrm{ha}^{-1}$.

O número de frutos por planta foi determinado pela contagem de todos os frutos passíveis a serem comercializados. A estimativa de produtividade foi obtida multiplicando a produção média por planta pelo número de plantas por hectare (666 plantas ha-1), O peso médio dos frutos foi definido pela divisão do peso total pelo número de frutos por planta. Os parâmetros diâmetros longitudinal, transversal e a espessura da casca foram obtidos com o auxílio de paquímetro digital marca Digimes ${ }^{\circledR}$ modelo $0-150 \mathrm{~mm} / 6$. As porcentagens de casca, semente e suco foram determinados a partir da pesagem dos componentes em balança digital marca Secura ${ }^{\circledR}$ modelo Segura 3102-1CIT, fazendo as devidas proporções. O teor de sólidos solúveis totais foi medido, sem diluição, por meio de um refratômetro digital marca Megabrix ${ }^{\circledR}$ modelo BZWHN1, com compensação automática de temperatura. A acidez total titulável foi determinada usando $5 \mathrm{~mL}$ de suco, fenolftaleína como indicador e titulação com $\mathrm{NaOH}$ a $0,1 \mathrm{~N}$. O pH do suco foi obtido pela leitura direta em $\mathrm{pH}$-metro digital de bancada marca Phtek ${ }^{\circledR}$ modelo PHS-3B.

Os resultados foram submetidos à análise de variância (teste $\mathrm{F}$ a 5\%), e as médias dos dados comparadas pelo teste de Sccott-Knott, a 5\% de probabilidade. O programa utilizado para as análises estatísticas foi o SISVAR $^{\circledR}$ (FERREIRA 2011).

\section{RESULTADOS E DISCUSSÃO}

As plantas que foram a campo com 125 dias após semeadura e aquelas que foram plantadas com 100 dias após semeadura iniciaram a maturação dos frutos em fevereiro de 2012. Os frutos das plantas oriundas das mudas com idade de 75 dias e as mudas com 50 dias iniciaram processo de maturação em março de 2012, enquanto isso, as plantas originadas a partir de mudas com idade de 25 dias iniciaram o mesmo processo em abril de 2012.

De acordo com a análise de variância, foram detectadas diferenças significativas (teste $\mathrm{F}, \mathrm{p}<0,05$ ) para todas as características avaliadas, com exceção do $\mathrm{pH}$.

$\mathrm{Na}$ Tabela 2, observa-se que as mudas foram levadas ao campo com maior idade (100 e 125 dias após emergência), produziram os frutos com maior massa fresca 189,50 e $201,75 \mathrm{~g}$. O índice de formato de fruto foi semelhante para todos os tratamentos, enquanto que a menor espessura de casca foi obtida em frutos dos tratamentos 3,4 e 5 .

O maior valor encontrado para a característica massa fresca do fruto foi de $201,75 \mathrm{~g}$, obtido em plantas formadas com mudas de 25 dias (Tabela 2). Esse dado é superior aos encontrados por NASCIMENTO et al. (2003), HAFLE et al. (2009) e CUNHA (2013), que obtiveram 193, 161,6 e 123,8 g em média de massa fresca do fruto para a cultivar Redondo Amarelo, respectivamente. Para LÚCIO et al. (2013), o comprimento e o diâmetro do fruto, a espessura da casca e a percentagem de polpa têm alta correlação com a massa fresca total de frutos de maracujá. Tal característica é fundamental, pois frutos maiores e com maior massa são preferidos no mercado de frutas, alcançando maiores cotações de preços no mercado tanto local quanto nacional.

Os diâmetros, tanto transversal quanto longitudinal foram maiores em frutos colhidos no tratamento $5(8,5 \mathrm{~cm}$ e $7,25 \mathrm{~cm})$ (Tabela 2). Em trabalho realizado por PENHA et al. (2013), os autores observaram que a cultivar BRS Gigante Amarelo apresentou maior comprimento e maior diâmetro de frutos, comparado a outras cultivares lançadas no mercado, no entanto os autores trabalharam com mudas convencionais. Essa característica torna-se extremamente desejável, uma vez que os frutos do maracujazeiro são classificados comercialmente em 
Tabela 2 - Massa fresca do fruto (MFF) em (g), diâmetro longitudinal (DL) e transversal (DT) em (cm), índice de formato do fruto (IFF) em (cm) e espessura da casca (EC) em (mm), em frutos de maracujá amarelo com cultivo de mudas de diferentes idades, após emergência. Lavras, MG, 2012.

Table 2 - Fresh fruit mass (MFF) in (g), longitudinal diameter (DL) and transverse (DT) in (cm), fruit shape index $(I F F)$ in $(\mathrm{cm})$ and thickness of the shell $(E C)(\mathrm{mm})$ in yellow passion fruit with different aged seedling cultivation, after emergence. Lavras, MG, 2012.

\begin{tabular}{cccccc}
\hline Tratamentos & MFF $(\mathrm{g})$ & DL $(\mathrm{cm})$ & DT $(\mathrm{cm})$ & IFF $(\mathrm{cm})$ & EC $(\mathrm{mm})$ \\
\hline 25 & $93,50 \mathrm{c}$ & $7,25 \mathrm{~b}$ & $6,0 \mathrm{c}$ & $1,2 \mathrm{a}$ & $8,20 \mathrm{~b}$ \\
50 & $103,75 \mathrm{c}$ & $7,65 \mathrm{~b}$ & $6,50 \mathrm{~b}$ & $1,17 \mathrm{a}$ & $7,00 \mathrm{~b}$ \\
75 & $157,25 \mathrm{~b}$ & $7,00 \mathrm{~b}$ & $7,00 \mathrm{~b}$ & $1,0 \mathrm{a}$ & $5,07 \mathrm{a}$ \\
100 & $189,50 \mathrm{a}$ & $7,95 \mathrm{a}$ & $6,25 \mathrm{~b}$ & $1,27 \mathrm{a}$ & $6,02 \mathrm{a}$ \\
125 & $201,75 \mathrm{a}$ & $8,50 \mathrm{a}$ & $7,25 \mathrm{a}$ & $1,17 \mathrm{a}$ & $5,90 \mathrm{a}$ \\
\hline $\mathrm{CV}(\%)$ & 19,71 & 10,58 & 11,47 & 10,23 & 12,21 \\
\hline
\end{tabular}

Médias com a mesma letra na coluna não diferem entre si pelo teste Scott-Knott, em 5\% de probabilidade.

relação à medida de seu diâmetro (KRAUSE et al. 2012).

No que se diz respeito ao índice de formato do fruto (IFF), esse é um parâmetro físico importante para frutos destinados ao mercado in natura. Valores próximos de 1,0 indicam que os frutos possuem formatos mais arredondados e acima formato oblongo, (FORTALEZA et al. 2005). Conforme o mesmo autor, frutos arredondados apresentam até $10 \%$ menos de polpa que frutos oblongos. No presente experimento todos os tratamentos apresentaram índice de formato acima de 1,0 apresentando formato oblongo (Tabela 2).

Todos os frutos estão de acordo com o Programa Brasileiro para a Melhoria dos Padrões Comerciais e Embalagens de Hortigranjeiros (HORTIBRASIL 2016), as classes são determinadas, usando uma escala numérica (1-5), pela medida do diâmetro equatorial (transversal) do fruto. Os frutos colhidos e analisados para todos os tratamentos pertencem à classe 3 e 4, ficando dentro de um padrão bom de classificação.

Para espessura da casca dos frutos, os tratamentos com mudas mais novas, e que formaram os tratamentos 1 e 2, (Tabela 2) apresentaram maior espessura, característica indesejada pelo consumidor, uma vez que para comercialização existe uma preferência por frutos com casca mais fina, por apresentarem maior rendimento de polpa por quilograma adquirido (BORGES et al. 2003).

Não houve diferença entre os tratamentos para a característica do $\mathrm{pH}$ dos frutos (Tabela 3 ). No entanto a média dos valores de $\mathrm{pH}$ foi de 3,00 e se manteve dentro dos limites estabelecidos pela legislação brasileira, que estabelece a faixa de 2,7 a 3,8 para polpa de maracujá (BRASIL 2000).

Em relação ao SST, frutos provenientes do cultivo com mudas com idades de 75, 100 e 125 dias, apresentaram maior SST e relação SST/ATT. Esta resposta é altamente desejável, pois a relação SST/ ATT dos frutos é uma característica química bastante importante para avaliar a qualidade do maracujá, por permitir maior sabor dos frutos. Para FOLEGATTI \& MATSUURA (2002), valores de SST/ATT entre 3,4 e 4,5 evidenciam frutos com qualidade adequada tanto para o consumo in natura como para o processamento do fruto.

De acordo com NASCIMENTO et al. (2003), para a indústria e o mercado de frutos in natura são necessários cerca de $11 \mathrm{~kg}$ de frutos de maracujáamarelo com SST entre 11 e 12\% para obtenção de 1 $\mathrm{kg}$ de suco concentrado a $50^{\circ} \mathrm{Brix}$. Assim, quanto mais alto for o teor de SST, menor a quantidade de frutos necessária para a concentração do suco. Segundo PIO et al. (2003), a relação SST/ATT é um importante atributo qualitativo, por indicar o sabor do fruto, o qual é resultado da contribuição dos componentes responsáveis pela acidez e doçura.

A acidez total encontrada nos frutos dos tratamentos formado por mudas com maior idade foram semelhantes aos resultados encontrados por ABREU et al. (2009), com a cultivar BRS Gigante. Esta cultivar apresentou média de acidez total de 3,88\%, o que pode ser explicado pela grande variabilidade em função dos diferentes genótipos de maracujá. A acidez 
Tabela 3 - Potencial Hidrogeniônico $(\mathrm{pH})$, sólidos solúveis titulais (SST), acidez titulável (AT) e relação (SST/ ATT) em frutos de maracujá-amarelo com cultivo de mudas em diferentes idades, após emergência. Lavras, MG, 2012.

Table 3 - Hydrogen Potential (pH), soluble solids holders (SST), titratable acidity (AT) and (SST/ATT) in yellow passion fruit with seedling cultivation at different ages after emergence, $M G, 2012$.

\begin{tabular}{cllll}
\hline Tratamentos & $\mathrm{pH}$ & SST & AT (\%) & SST/ATT \\
\hline 25 & $3,00 \mathrm{a}$ & $11,75 \mathrm{~b}$ & $4,93 \mathrm{a}$ & $2,38 \mathrm{~b}$ \\
50 & $2,75 \mathrm{a}$ & $11,73 \mathrm{~b}$ & $4,33 \mathrm{a}$ & $2,70 \mathrm{~b}$ \\
75 & $3,00 \mathrm{a}$ & $13,00 \mathrm{a}$ & $3,00 \mathrm{~b}$ & $4,33 \mathrm{a}$ \\
100 & $3,25 \mathrm{a}$ & $13,90 \mathrm{a}$ & $3,60 \mathrm{~b}$ & $3,86 \mathrm{a}$ \\
125 & $3,00 \mathrm{a}$ & $13,78 \mathrm{a}$ & $3,23 \mathrm{~b}$ & $4,46 \mathrm{a}$ \\
\hline $\mathrm{CV}(\%)$ & 10,3 & 5,32 & 10,09 & 12,9 \\
\hline
\end{tabular}

Médias com a mesma letra na coluna não diferem entre si pelo teste Scott-Knott, em 5\% de probabilidade.

também está relacionada com o estádio de maturação e da época de colheita dos frutos. Para COELHO et al. (2010), o maracujá-amarelo comum colhido maduro atinge $4,42 \%$ de acidez. Segundo SILVA et al. (2008), os maracujás colhidos mais verdes no inverno são mais ácidos que os da safra de verão; contudo, a acidez reduz à medida que os frutos amadurecem. Os maracujás comuns colhidos maduros, na safra de verão, apresentam média de acidez de 4,09\% e os colhidos na safra de inverno, alcançam 4,64\% de acidez.

O maior rendimento de casca foi observado nos frutos oriundos dos tratamentos 1,2 e 3 , enquanto que os menores valores foram observados nos frutos colhidos nos tratamentos 4 e 5 (Tabela 4). Os frutos colhidos em plantas crescidas a partir de mudas de 100 e 125 dias apresentaram a maior porcentagem de suco e sementes, fato atribuído à presença do maior número de sementes nestes frutos, uma vez que a polpa está aderida às sementes e, consequentemente, frutos com maior porcentagem de sementes, possuem maior rendimento de suco.

Frutos com maior rendimento de casca é indesejada, pois o que se pretende em frutos de maracujá é uma quantidade maior de suco e pouca casca. As plantas avaliadas no presente trabalho apresentaram diâmetro casca grande, principalmente aquelas oriundas de mudas com 25 dias após emergência. Estas produziram frutos com casca de até $8,20 \mathrm{~mm}$ (Tabela 2).

Para comercialização, existe uma preferência por frutos com casca mais fina por apresentarem maior rendimento de polpa por quilograma adquirido.
Verifica-se no trabalho realizado por BORGES et al. (2003), avaliando adubação em maracujazeiroamarelo, que os frutos apresentaram espessura média $8 \mathrm{~mm}$. BRITO et al. (2005) encontraram diferenças na espessura da casca de frutos de maracujazeiro utilizando tratamentos com diferentes fontes e doses de adubos orgânicos, indicando que esta característica está diretamente ligada aos fatores nutricionais.

Uma das características mais importantes em se tratando do maracujá é o rendimento de suco. Neste trabalho foram encontrados valores que variaram entre $31,4 \%$ a $33,33 \%$ de rendimento nos frutos de plantas originadas de mudas transplantadas com idade de 100 e 120 dias (Tabela 4). Esses resultados foram semelhantes aos encontrados por BORGES et al. (2003) que em experimento de adubação com nitrogênio e potássio obtiveram 32,8 a $34,3 \%$ de rendimento de suco em maracujazeiro-amarelo, assim como HAFLE et al. (2009) que obtiveram em média o valor de $32,42 \%$ em frutos de plantas submetidas a diferentes tipos de podas. Todos estes autores utilizaram tratos culturais convencionais à cultura, $\mathrm{o}$ que não foi realizado no presente experimento visando diminuir custos para o produtor.

As plantas originadas de mudas com idades de 100 e 125 dias obtiveram maior quantidade de frutos por planta 66,2 e 69,5 frutos, respectivamente, como pode ser observado na (Figura 1). Em geral, houve aumento de aproximadamente 37,2 frutos por planta em relação ao tratamento 1 , estas produziram 32,3 frutos por planta.

A menor produção de frutos por planta observada em alguns tratamentos $(1=(32,3$ frutos/ 
Tabela 4 - Rendimento de casca, suco e sementes de maracujá-amarelo cultivado utilizando mudas em diferentes idades, após emergência. Lavras, MG, 2012.

Table 4 - Yield of the shell, juice and yellow passion fruit seeds grown using seedlings at different ages. Lavras, $M G, 2012$.

\begin{tabular}{cccc}
\hline & \multicolumn{3}{c}{ Rendimento (\%) } \\
\hline Tratamentos & Casca & Suco & Sementes \\
\hline 25 & $69,63 \mathrm{~b}$ & $26,78 \mathrm{~b}$ & $3,59 \mathrm{~b}$ \\
50 & $67,83 \mathrm{~b}$ & $27,89 \mathrm{~b}$ & $4,28 \mathrm{~b}$ \\
75 & $66,91 \mathrm{~b}$ & $26,04 \mathrm{~b}$ & $4,05 \mathrm{~b}$ \\
100 & $62,55 \mathrm{a}$ & $31,44 \mathrm{a}$ & $6,01 \mathrm{a}$ \\
125 & $60,35 \mathrm{a}$ & $33,33 \mathrm{a}$ & $6,32 \mathrm{a}$ \\
\hline CV (\%) & 5,03 & 4,88 & 11,37 \\
\hline Média & 65,45 & 29,69 & 3,64 \\
\hline
\end{tabular}

Médias com a mesma letra na coluna não diferem entre si pelo teste Scott-Knott, em 5\% de probabilidade.

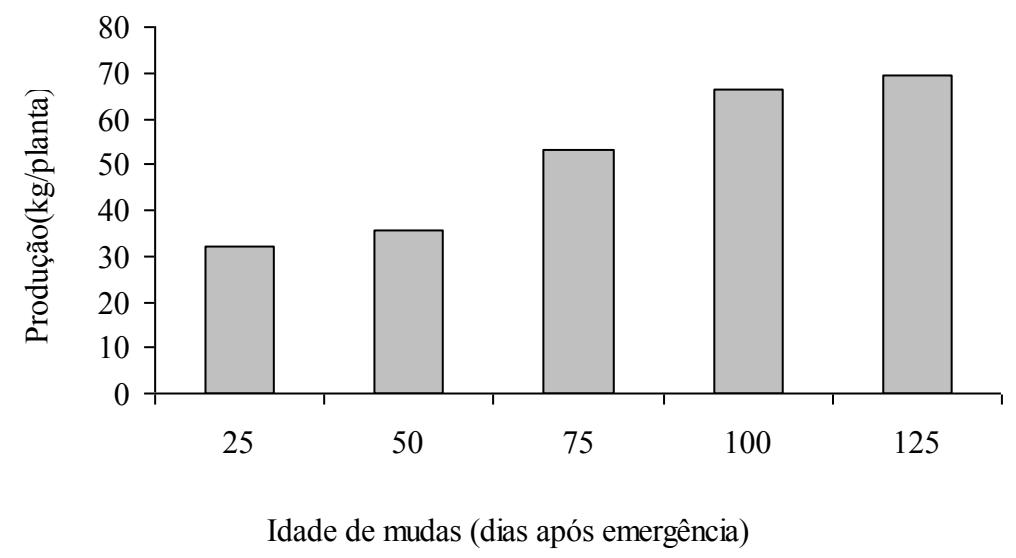

Figura 1 - Produção do maracujá-amarelo cultivado com uso de mudas em diferentes idades. Lavras, MG, 2012. Figure 1 - Production of yellow passion fruit cultivated with the use of seedlings at different ages, Lavras, MG, 2012.

planta), $2=(35,8$ frutos/planta $)$ e $3=53,2$ frutos $/$ planta) pode estar relacionada a diversos fatores, entre os quais ataques de pragas e doenças, já que essas mudas foram levadas a campo mais novas e consequentemente ficaram mais susceptíveis a qualquer adversidade no ambiente de cultivo.

Observa-se na (Figura 2) que as maiores produtividades de frutos ocorreram nos tratamentos com mudas tardias, $\left(4=12.544\right.$ e $\left.5=14.021 \mathrm{~kg} \mathrm{ha}^{-1}\right)$.
Para os tratamentos com mudas jovens, menor porte e idade a produtividade decresceu, ficando em 3.030, 3.683 e $8.367 \mathrm{~kg} \mathrm{ha}^{-1}$, para os tratamentos 1,2 e 3 , nessa ordem.

A produtividade obtida no maracujazeiro no cultivo de mudas tardia está de acordo com a média nacional, que em 2013 alcançou $13.416 \mathrm{~kg} \mathrm{ha}^{-1}$ (IBGE 2013), diferentemente daquelas obtidas em ensaios das mudas jovens. Também estão semelhantes aos 


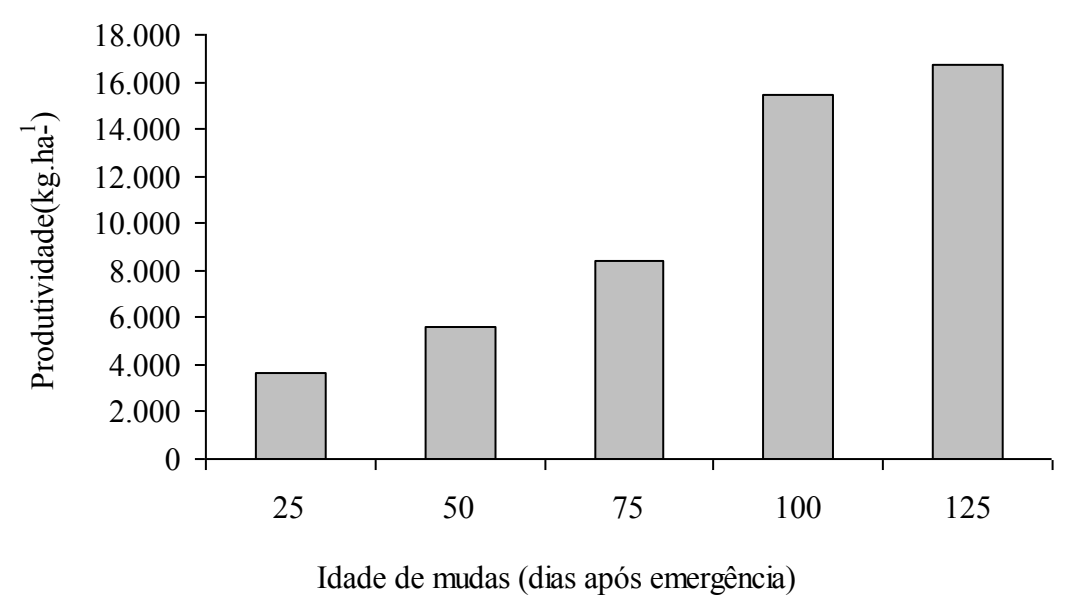

Figura 2 - Produtividade do maracujá-amarelo cultivado com uso de mudas em diferentes idades. Lavras, MG, 2012.

Figure 2 - Production the yellow passion fruit cultivated with the use of seedlings at different ages, Lavras, $M G, 2012$.

valores encontrados por HAFLE et al. (2009), quando os autores utilizaram diferentes podas em ramos produtivos obtiveram maior produtividade quando deixaram maior número de ramos terciários por planta, no entanto foi utilizada mudas convencionais. Já ARAÚJO NETO et al. (2005), obtiveram produtividade de $9.282 \mathrm{~kg} \mathrm{ha}^{-1}$, na primeira safra, utilizando adensamento e DAMATTO JUNIOR et al. (2005) obtiveram produção de $15,94 \mathrm{~kg} /$ planta quando as plantas de maracujazeiro doce foram adubadas com a dose de $100 \%$ de adubo orgânico ( 80 g N/planta).

De acordo com LIMA \& BORGES (2002), são vários os fatores que podem interferir na produtividade e qualidade dos frutos do maracujazeiro, sendo os principais: temperatura, precipitação, umidade relativa, luminosidade e manejo cultural.

Foi observado no presente experimento que as mudas mais novas e de porte menor durante o período produtivo estavam mais susceptíveis ao ataque de pragas e doenças prejudicando a qualidade dos frutos, ao passo que as mudas com idade maior ( 100 e 125 dias após emergência) foram levadas a campo já adultas com 1,50 e 1,90 m de altura, sendo beneficiadas pela condição do cultivo protegido quando na fase de desenvolvimento. Durante o período experimental em campo, ocorreram ataques de lagartas desfolhadoras, percevejos e abelhas, cujos controles adotados foram os de forma manual. No entanto esses podem ter influenciado na produtividade, qualidade e aparência dos frutos dos tratamentos.

\section{CONCLUSÃO}

A utilização de mudas com idades de 100 e 125 dias após emergência no cultivo do maracujazeiroamarelo apresentou resultados satisfatórios para todas as características avaliadas, deduzindo-se ser viável sua utilização.

O cultivo do maracujazeiro-amarelo formado com mudas de menor idade, em relação às demais idades obtiveram uma baixa produtividade, frutos menores e com menor rendimento de suco.

\section{REFERÊNCIAS}

ABREU SPM et al. 2009. Características físico-químicas de cinco genótipos de maracujazeiro-azedo cultivados no Distrito Federal. Revista Brasileira de Fruticultura 31: 487491.

AGRIANUAL. 2015. Anuário estatístico do Brasil. São Paulo: FNP Consultoria \& Comércio. 536p.

ARAÚJO NETO SE et al. 2005. Adensamento, desbaste e análise econômica na produção do maracujazeiro-amarelo. Revista Brasileira de Fruticultura 27: 394-398.

BERNACCI LC et al. 2008. Passiflora edulis Sims: the correct taxonomic way to cite the yellow passion fruit (and of others colors). Revista Brasileira de Fruticultura 30: 566-576. 
BORGES AL et al. 2003. Produtividade e qualidade de maracujá-amarelo irrigado, adubado com nitrogênio e potássio. Revista Brasileira de Fruticultura 25: 259-262.

BRASIL. 2000. Ministério da Agricultura e do Abastecimento. Leis, Decretos, etc. Instrução Normativa NQ 1, de 7 de Janeiro de 2000. Regulamento técnico geral para fixação dos padrões de identidade e qualidade para polpa de frutas. Diário Oficial da União, NQ 6, Brasília, 10 de Janeiro de 2000. Seção 1, p.54-58.

BRITO MEB et al. 2005. Rendimento e qualidade da fruta do maracujazeiro-amarelo adubado com potássio, esterco de frango e de ovino. Revista Brasileira de Fruticultura 27: 260-263.

COELHO AA et al. 2010. Qualidade do suco de maracujáamarelo em diferentes pontos de colheita e após o amadurecimento. Ciência e Agrotecnologia 34: 722-729.

CUNHA M. 2013. Produtividade e características de frutos de pomares de maracujá implantados com sementes originais e reaproveitadas do híbrido BRS Gigante Amarelo. Dissertação (Mestrado em Agronomia). Brasília: UnB. 64p.

DAMATTO JUNIOR ER et al. 2005. Adubação orgânica na produção e qualidade de frutos de maracujá-doce. Revista Brasileira de Fruticultura 27: 188-190.

FERREIRA DF. 2011. Sisvar: a computer statistical analysis system. Ciência e Agrotecnologia 35: 1039-1042. FOLEGATTI MIS \& MATSUURAFCAU. 2002. Maracujá. Pós-colheita. Brasília: Embrapa Informação Tecnológica. 51p. (Frutas do Brasil, 23).

FORTALEZA JM et al. 2005. Características físicas e químicas em nove genótipos de maracujá azedo cultivado sob três níveis de adubação potássica. Revista Brasileira de Fruticultura 27: 124-127.

HAFLE OM et al. 2009. Produtividade e qualidade de frutos do maracujazeiro-amarelo submetido à poda de ramos produtivos. Revista Brasileira de Fruticultura 31: 763-770.

HORTIBRASIL. 2016. Programa Brasileiro para Modernização da Agricultura. Maracujá-azedo:cartilha para classificação. Disponível em: http://www.hortibrasil. org.br. Acesso em: 12 jul. 2016.

IBGE. 2013. Instituto Brasileiro de Geografia e Estatística. Produção Agrícola Municipal, Disponível em: ftp://ftp. ibge.gov.br/Producao_Agrico la/Producao_Agricola Municipal_\%5 Banual\%5D/2013/tabelas_pdf/tabela0 3.pdf. Acesso em: 2 jul. 2016.

KRAUSE W et al. 2012. Produtividade e qualidade de frutos de cultivares de maracujazeiro-amarelo com ou sem polinização artificial. Pesquisa Agropecuária Brasileira 47: 1737-1742.

LIMA AA \& BORGES AL. 2002. Solo e clima. In: LIMA AA (Ed. Maracujá produção: aspectos técnicos. Brasília: EMBRAPA. p.25-28.

LÚCIO AD et al. 2013. Relações entre os caracteres de maracujazeiro-azedo. Ciência Rural 43: 225-232.
MELETTI LMM. 2011. Avanços na cultura do maracujá no Brasil. Revista Brasileira de Fruticultura 33: 83-91.

NASCIMENTO WMO et al. 2003. Seleção de progênies de maracujazeiro-amarelo (Passiflora edulis f. flavicarpa) quanto à qualidade de frutos. Revista Brasileira de Fruticultura 25: 186-188.

NEVES LG et al. 2010. Avaliação da repetibilidade no melhoramento de famílias de maracujazeiro. Revista Ceres 57: 480-485.

PIO R et al. 2003. Caracterização físico-química dos frutos de sete seleções de maracujazeiro-amarelo para a região de Lavras - MG. Ceres 50: 573-582.

SILVA TV et al. 2008. Determinação da escala de coloração da casca e do rendimento em suco do maracujá-amarelo em diferentes épocas de colheita. Revista Brasileira de Fruticultura 30: 880-884. 